University of Nebraska - Lincoln

DigitalCommons@University of Nebraska - Lincoln

Publications, Agencies and Staff of the U.S.

Department of Commerce

U.S. Department of Commerce

$2-2002$

\title{
Relationship of Effective to Census Size in Fluctuating Populations
}

Steven Kalinowski

NOAA, steven.kalinowski@noaa.gov

Robin Waples

NOAA, robin.waples@noaa.gov

Follow this and additional works at: https://digitalcommons.unl.edu/usdeptcommercepub

Kalinowski, Steven and Waples, Robin, "Relationship of Effective to Census Size in Fluctuating Populations" (2002). Publications, Agencies and Staff of the U.S. Department of Commerce. 435. https://digitalcommons.unl.edu/usdeptcommercepub/435

This Article is brought to you for free and open access by the U.S. Department of Commerce at DigitalCommons@University of Nebraska - Lincoln. It has been accepted for inclusion in Publications, Agencies and Staff of the U.S. Department of Commerce by an authorized administrator of DigitalCommons@University of Nebraska - Lincoln. 


\title{
Relationship of Effective to Census Size in Fluctuating Populations
}

\author{
STEVEN T. KALINOWSKI* AND ROBIN S. WAPLES
}

Conservation Biology Division, Northwest Fisheries Science Center, National Marine Fisheries Service, National Oceanic and Atmospheric Administration, 2725 Montlake Boulevard East, Seattle, WA 98112, U.S.A.

\begin{abstract}
The effective size of a population $\left(\mathrm{N}_{\mathrm{e}}\right)$ rather than the census size $(\mathrm{N})$ determines its rate of genetic drift. Knowing the ratio of effective to census size, $\mathrm{N}_{\mathrm{e}} / \mathrm{N}$, is useful for estimating the effective size of a population from census data and for examining bow different ecological factors influence effective size. Two different multigenerational ratios have been used in the literature based on either the arithmetic mean or the harmonic mean in the denominator. We clarify the interpretation and meaning of these ratios. The arithmetic mean $\mathrm{N}_{\mathrm{e}} / \mathrm{N}$ ratio compares the total number of real individuals to the long-term effective size of the population. The harmonic mean $\mathrm{N}_{\mathrm{e}} / \mathrm{N}$ ratio summarizes variation in the $\mathrm{N}_{\mathrm{e}} / \mathrm{N}$ ratio for each generation. In addition, we show that the ratio of the harmonic mean population size to the arithmetic mean population size provides a useful measure of how much fluctuation in size reduced the effective size of a population. We discuss applications of these ratios and emphasize bow to use the barmonic mean $\mathrm{N}_{\mathrm{e}} / \mathrm{N}$ ratio to estimate the effective size of a population over a period of time for which census counts bave been collected.
\end{abstract}

Relación entre Tamaño Efectivo y Censal en Poblaciones Fluctuantes

Resumen: El tamaño efectivo de una población ( $\mathrm{N}_{\mathrm{e}}$ ) y no el tamaño censal ( $\mathrm{N}$ ) determina su tasa de deriva génica. Conocer la proporción del tamaño efectivo con el censal, $\mathrm{N}_{\mathrm{e}} / \mathrm{N}$, es de utilidad para estimar el tamaño efectivo de una población a partir de datos censales y para examinar como influyen en el tamaño efectivo diferentes factores ecológicos. Se han utilizado dos diferentes proporciones $\mathrm{N}_{\mathrm{e}} / \mathrm{N}$ en la literatura basados en la media aritmética o en la media armónica en el denominador. Aclaramos la interpretación y significado de esas proporciones. La media aritmética en la relación $\mathrm{N}_{\mathrm{e}} / \mathrm{N}$ compara el total de individuos reales con el tamaño efectivo de la población a largo plazo. La relación $\mathrm{N}_{\mathrm{e}} / \mathrm{N}$ con base en la media armónica sintetiza la variación en la proporción $\mathrm{N}_{\mathrm{e}} / \mathrm{N}$ para cada generación. Adicionalmente, mostramos que la proporción de la media armónica del tamaño poblacional con la media aritmética del tamaño poblacional es una medida útil de como la fluctuación en tamaño reduce el tamaño efectivo de una población. Discutimos las aplicaciones de estas proporciones y enfatizamos como utilizar la proporción $\mathrm{N}_{\mathrm{e}} / \mathrm{N}$ basada en la media armónica para estimar el tamaño efectivo de una población en un período de tiempo en el cual se han colectado datos censales.

\section{Introduction}

Some of the most important work in conservation genetics has explored interactions between population size, genetic diversity, and population fitness. Small population size can lead to loss of neutral genetic variation, fix-

*email steven.kalinowski@noaa.gov

Paper submitted April 4, 2000; revised manuscript accepted March 28, 2001. ation of mildly deleterious alleles, and thereby reduced population fitness. The rate of this process depends on the effective size of a population, $N_{e}$, rather than the actual number of living individuals, $N$, making the effective size of a population one of most fundamental parameters in evolutionary and conservation biology.

The effective size of a population is the size of an ideal population that would be affected by genetic drift at the same rate as the actual population (Wright 1931). The ideal population with which natural populations are com- 
pared has discrete (nonoverlapping) generations, an even sex ratio, constant size, random union of gametes, and random survivorship of offspring (Wright 1931). Although intensive management can potentially cause the effective size of a population to be greater than the census size (e.g., by equalizing the reproductive success of all individuals), deviation from ideal conditions in nature typically causes $N_{e}$ to be $<N$. Unfortunately, directly estimating the effective size of natural populations is difficult. Estimating $N_{e}$ requires either genetic data (for review see Neigel 1996) or demographic data (for review see Caballero 1994) that typically are difficult to obtain. These difficulties often motivate use of census data to estimate $N_{e}$ by multiplying a measure of census size by an estimate of the ratio of effective size to census size, $N_{e} / N$.

Although the concept of effective population size is elegantly simple, many applications of the theory are quite complex, and even a strategy as apparently straightforward as multiplying a census count by a ratio can be complicated. Consider recent theoretical and empirical efforts to estimate $N_{e} / N$ in natural populations and describe its properties. Theoretical examination of uneven sex ratios, nonrandom mating, overlapping generations, and variation in family size by Nunney $(1991,1993$, 1996) suggests that $N_{e} / N$ should be approximately 0.5 in most populations and only rarely $<0.25$. Therefore, when Frankham (1995) examined a large number of empirical estimates of $N_{e} / N$ and found that $N_{e} / N$ ratios have an average value of 0.1 in nature, he concluded that wildlife populations generally have smaller effective sizes than predicted by theory. Vucetich et al. (1997) resolved this apparent discrepancy by pointing out that the theory of Nunney $(1991,1993,1996)$ assumes constant population size. When Vucetich et al. accounted for population fluctuation, empirical estimates were in rough agreement with theoretical expectations.

Although such research has considerably advanced our understanding of effective population size and its conservation applications, several important issues relating to multigeneration $N_{e} / N$ ratios remain unresolved. First, no one has defined what $N_{e} / N$ represents in fluctuating populations in terms of real and ideal individuals. Second, there is no comprehensive framework to relate how inter- and intrageneration demographic processes interact to determine $N_{e} / N$. Most previous research either relates to one generation, assumes that $N_{e} / N$ for each generation is constant, or describes the cumulative effect of both processes. Third, discussion of how to use $N_{e} / N$ to estimate effective sizes from census counts has left a few important issues unclear.

We address each of these three issues. We propose definitions for $N_{e} / N$ in fluctuating populations in terms of real and ideal individuals and then derive mathematical formulae for these definitions. Although the biological definitions for these $N_{e} / N$ ratios are novel, we found that they naturally led to the formulas for the two $N_{e} / N$ ratios that are currently in use. We review some of the properties of these ratios and describe how they can be used in a few conservation applications.

\section{Defining the Ratio of Long-Term Effective Size to Census Size}

\section{Effective Population Sizes in Fluctuating Populations}

Effective population sizes can be defined for at least three different time frames: a single generation, several generations, or a large number of generations. At the shortest time frame is the effective population size of a single generation, $N_{e, t}$ (where $t$ indicates the $t$ th generation). The effective size of a population over $k$ generations is approximately the harmonic mean of the singlegeneration effective sizes (Wright 1938; Crow \& Kimura 1970; Motro \& Thompson 1982):

$$
\left(N_{e}\right)_{k} \approx \operatorname{harmonic} \operatorname{mean}\left(N_{e, 1}, N_{e, 2} \ldots N_{e, k}\right) .
$$

We call this effective size the multigeneration effective size. The multigeneration effective population size describes a population over a specific number of generations-for example, the effective population size of the black-footed ferret (Mustela nigripes) captive breeding program or the effective size of the grizzly bear (Ursus arctos) population in Montana since 1950. Lastly, the effective size of a population over a large or perhaps indefinite number of generations, either in the past or into the future, is often of interest-for example, the effective size of bighorn sheep (Ovis canadensis) populations since the Pleistocene or the expected future effective size of populations given current management practices. In many circumstances this effective size is essentially equivalent to $\left(N_{e}\right)_{k}$ defined over a large number of generations. We call this effective population size the long-term effective size and represent it by $\left(N_{e}\right)_{a s}$ to emphasize that it is often the asymptotic value of $\left(N_{e}\right)_{k}$ as $k$ increases.

\section{Ratios of Effective Population Size to Census Size in Fluctuating Populations}

The ratio of effective to census size for one generation, $N_{e, t} / N_{t}$, is useful in summarizing the cumulative effects of sex ratio and variance in family size for one generation. Because $N_{e, t} / N_{t}$ is defined for only one generation, it is not affected by and does not account for population fluctuation. Defining a multigeneration analogue of $N_{e, t} / N_{t}$ can be done in at least two ways.

Let us first define a multigeneration $N_{e, t} / N_{t}$ ratio as a representative value of $N_{e, t} / N_{t}$ during $k$ generations. In real populations census sizes, effective sizes, and their ratios will probably vary each generation. The interaction of these variables can be described by rewriting equation 1 as 
$\left(N_{e}\right)_{k}=$ harmonic mean $\left(N_{1} \frac{N_{e, 1}}{N_{1}}, N_{2} \frac{N_{e, 2}}{N_{2}} \ldots N_{k} \frac{N_{e, k}}{N_{k}}\right)$

Let us define a multigeneration $N_{e} / N$ ratio, $\alpha_{k}$ as the value that $N_{e, t} / N_{t}$ would have in equation 2 if the ratio were constant each generation. This is analogous to defining $\left(N_{e}\right)_{k}$ as the value that $N_{e, t}$ would have if $N_{e, t}$ were constant each generation. Therefore, let us define $\alpha_{k}$ as the ratio that satisfies the relationship

$$
\left(N_{e}\right)_{k}=\text { harmonic mean }\left(N_{1} \alpha_{k}, N_{2} \alpha_{k} \ldots N_{k} \alpha_{k}\right),
$$

where $k$ indicates the number of generations for which $\alpha_{k}$ is defined. From equation 3 we obtain

$$
\alpha_{k}=\frac{\left(N_{e}\right)_{k}}{(\tilde{N})_{k}},
$$

where $(\tilde{\mathrm{N}})_{k}$ is the harmonic mean census count over $k$ generations. Because $\alpha_{k}$ is similar to a weighted average of $N_{e, t} / N_{t}$ values, it measures the cumulative effect of intrageneration departures from ideal conditions (sex ratio, variance in family size) on $\left(N_{e}\right)_{k}$ in fluctuating populations. Population fluctuation also affects $\alpha_{k}$, but only indirectly through interactions with variation in $N_{e, t} / N_{t}$.

Alternatively, we can define a multigeneration $N_{e, t} / N_{t}$ ratio to describe how all real individuals born during $k$ generations compared with their ideal counterparts. The total number of real individuals living during $k$ generations is

$$
\sum_{t=1}^{k} N_{t},
$$

and the total number of ideal individuals "living" in the same period of time is $k\left(N_{e}\right)_{k}$. Therefore, the ratio of

$$
k\left(N_{e}\right)_{k} \text { to } \sum_{t=1}^{k} N_{t},
$$

which we will call $\beta_{k}$, serves as a reasonable comparison between ideal and real individuals. We obtain

$$
\beta_{k}=\frac{k\left(N_{e}\right)_{k}}{\sum_{t=1}^{k} N_{t}}=\frac{\left(N_{e}\right)_{k}}{(\bar{N})_{k}},
$$

where $(\bar{N})_{k}$ is the arithmetic mean census count over $k$ generations. The quantity $\beta_{k}$ represents the proportional contribution of each real individual (relative to an ideal individual) to the multigeneration effective size of a population. This definition incorporates the combined effect of both intergenerational and intragenerational departures from ideal conditions.

\section{Relationship between Inter- and Intrageneration Effects on $N_{e} / N$}

We defined $\alpha_{k}$ to describe how intrageneration effects influence $N_{e}$ and $\beta_{k}$ to describe the cumulative influence of both inter- and intrageneration effects on $N_{e}$. The ratios $\alpha_{k}$ and $\beta_{k}$ are related by

$$
\beta_{k}=\alpha_{k} \phi_{k}
$$

where $\phi_{k}=(\tilde{N})_{k} /(\bar{N})_{k}$. The ratio $\phi_{k}$ is a useful measure of how much the census count of a population fluctuates. If a population remains constant in size, $\phi_{k}=1.0$, whereas populations that fluctuate wildly will have values for $\phi_{k}$ close to 0.0 . The ratio $\alpha_{k}$ is affected by sex ratio and variance in family size; the ratio $\phi$ is affected by fluctuations in size. Equation 6, therefore, shows that $\beta_{k}$ is the product of both intra- $(\alpha)$ and intergeneration $(\phi)$ effects.

We can describe the relationship between $\left(N_{e}\right)_{k}$ and intra- and intergeneration effects by rewriting equation 6 as

$$
\left(N_{e}\right)_{k}=(\bar{N})_{k} \alpha_{k} \phi_{k}
$$

In equation 7 , the arithmetic mean population size, $(\bar{N})_{k}$, is the size that each generation would have if population size had been constant and the same total number of individuals were born. If the arithmetic mean population size is a reasonable description of the population's "normal" size, we can view $(\bar{N})_{k}$ as the effective size a population would have had if it had been ideal. If we view $(\bar{N})_{k}$ in this manner, then $\alpha_{k}$ and $\phi_{k}$ show how intra- and intergeneration effects, respectively, lower the effective size of a population.

But the arithmetic mean population size must not be accepted uncritically as the size a population would have if it were not fluctuating. For example, the arithmetic mean of the census counts 100, 100, 900, and 100 is 300 , but viewing 300 as the size the population would have if it did not fluctuate seems inappropriate. In a circumstance such as this, we may simply represent the effective population sizes of the fluctuating population by the harmonic mean population size and relate this to $\left(N_{e}\right)_{k}$ as

$$
\left(N_{e}\right)_{k}=(\tilde{N})_{k} \alpha_{k}
$$

Equation 8 does not contain a term indicating how much a population has fluctuated in size. This is because a population will have the same long-term effective size whether it has a constant population size of $K$ or a fluctuating population with a harmonic mean population size equal to $K$. This emphasizes that the familiar statement "population fluctuation reduces $N_{e}$ " compares a fluctuating population with one of constant size, the same total number of individuals, and the same $N_{e, t} / N_{t}$ ratios.

\section{Example: Applying Definitions of $\alpha, \beta$, and $\phi$ to Data}

An example (Table 1) illustrates what $\alpha, \beta$, and $\phi$ represent. Real populations often deviate from ideal populations in each of the ways described above, but let us examine a population that has only two non-ideal char- 
Table 1. Effective population size and ratios of effective population size to census size in four generations of a hypothetical population with nonoverlapping generations, an unequal sex ratio, and Poisson variation in reproductive success within sexes.

\begin{tabular}{|c|c|c|c|c|c|}
\hline 1 & 32 & 19 & 51 & 47.7 & 0.94 \\
\hline 2 & 19 & 3 & 22 & 10.4 & 0.47 \\
\hline 4 & 201 & 71 & 272 & 209.9 & 0.77 \\
\hline$(\bar{N})_{4}$ & & & 113 & & \\
\hline$(\tilde{N})_{4}$ & & & 51.2 & & \\
\hline$\phi_{4}=(\tilde{N})_{4} /(\bar{N})_{4}$ & & & & & 0.45 \\
\hline$\beta_{4}=\left(N_{e}\right)_{4} /(\bar{N})_{4}$ & & & & & 0.25 \\
\hline
\end{tabular}

acteristics: variable population size and an unequal sex ratio. The effective size of each generation of such a population is determined by the number of male and females according to the relationship

$$
N_{e, f}=\frac{4 N_{m, t} N_{f, t}}{N_{m, t}+N_{f, t}}
$$

(Wright 1938), where $N_{m, t}$ and $N_{f, t}$ indicate the number of males and females, respectively, in generation $t$. During the four generations covered in this example, the size of the population varied from 22 to 272 individuals, $N_{e, t}$ varied from 10.4 to 209.9 , and the ratio $N_{e, t} / N_{t}$ varied from 0.47 to 0.94 . The cumulative effect of the uneven sex ratio was to reduce $\left(N_{e}\right)_{4}$ by a factor of 0.56 (i.e., $\alpha_{4}=0.56$ indicates that $\left(N_{e}\right)_{4}$ is $56 \%$ of what $\left(N_{e}\right)_{4}$ would have been if the sex ratio had been 1:1 among the individuals mating each generation). This also means that, from a neutral genetic perspective, this population is equivalent to a population having the same census count as that in the example and a constant $N_{e, t} / N_{t}$ ratio of 0.56 each generation. The effect of population fluctuations was to reduce the effective size (compared with the arithmetic mean size) by a factor of 0.45 (i.e., $\phi_{4}=$ $0.45)$. The combined effect of both population fluctuation and sex ratio effects was to reduce the long-term effective size by a factor of $0.25((0.56)(0.45)=0.25)$, which is equal to $\beta_{4}$. Another way of viewing this population is that 452 individuals living during four generations passed on as much neutral genetic variation as four generations of 28.8 ideal individuals. Therefore, each of the real individuals living during these four generations was equivalent to 0.25 of an ideal individual.

\section{Relationship to Previous Research}

Previous empirical and theoretical work has focused on $\beta$. For example, Frankham (1995) and Vucetich et al. (1997) reviewed the value of $\beta$ across many taxa and examined how $\phi$ was related to $\beta$ by assuming that $N_{e, t} / N_{t}$ was constant. Vucetich and Waite (1998) examined the statistical properties of $\beta$. The ratio $\alpha$ has received less application and discussion, but Nunney (1996) used it in place of $N_{e, t} / N_{t}$ to factor out the effect of population fluctuations. Vucetich and Waite (1998) suggested that the arithmetic mean value of $N_{e, t} / N_{t}$ be used to summarize variation in $N_{e, t} / N_{t}$. Defining $\alpha$ this way will not satisfy equation 2 , however, and this approach should not be used.

The integration of intra- and intergeneration effects (equations $6,7,8$ ) on $N_{e}$ extends or complements previous formulations. In particular, $\alpha$ permits variation in $N_{e, t} / N_{t}$ to be summarized. The ratio $\phi$ is valuable as a measure of population fluctuation in a way that is relevant for effective size theory. But the standard deviation of the natural logarithm of population size can be used to approximate $\phi$ :

$$
\phi_{k} \approx \frac{1}{\left\{1+0.5\left[\ln (10) \sigma_{n}\right]^{2}\right\}^{2}}
$$

(Vucetich et al. 1997).

\section{Comparison of Properties of $\alpha, \beta$, and $\phi$}

\section{Response to Population Fluctuation}

One of the most important differences among $\alpha, \beta$, and $\phi$ is that $\alpha$ is not directly affected by population fluctuation, whereas $\beta$ and $\phi$ are. Consider an example (Table 2) of a population fluctuating in size but with $N_{e, t} / N_{t}$ equal to a constant value of 0.5 each generation, which might occur if mating patterns, variance in family success, and sex ratio were constant each generation. In this example, the single-generation effective population size, $N_{e, t}$, ranges from 60 to 600; the four-generation effective size, $\left(N_{e}\right)_{4}$, is approximately 104 . The ratio $\alpha_{4}$ is equal to 0.5 , the value of $N_{e, t} / N_{t}$ each generation. This is reassuring because $\alpha$ is defined as the value that $N_{e, t} / N_{t}$ would have if $N_{e, t} / N_{t}$ was constant. In this example, population fluctuation by itself reduced the effective size of this population by a factor of 0.48 (i.e., $\phi=0.48$ ). The cumulative 
Table 2. Example of a hypothetical population undergoing fluctuations in population size but having a constant $N_{e, t} / N_{t}$ ratio.

\begin{tabular}{lrcc}
\hline Generation & $\mathrm{N}_{\mathrm{t}}$ & $\mathrm{N}_{\mathrm{e}, \mathrm{t}}$ & $\mathrm{N}_{\mathrm{e}, \mathrm{t}} / \mathrm{N}_{\mathrm{t}}$ \\
\hline 1 & 120 & 60 & 0.5 \\
2 & 190 & 95 & 0.5 \\
3 & 1200 & 600 & 0.5 \\
4 & 210 & 105 & 0.5 \\
$(\bar{N})_{4}$ & 430 & & \\
$(\tilde{N})_{4}$ & 208.4 & & \\
$\left(N_{\mathrm{e}}\right)_{4}$ & & 104.2 & \\
$\alpha_{4}=\left(N_{e}\right)_{4} /(\tilde{N})_{4}$ & & & 0.50 \\
$\phi_{4}=(\tilde{N})_{4} /(\bar{N})_{4}$ & & & 0.48 \\
$\beta_{4}=\left(N_{e}\right)_{4} /(\bar{N})_{4}$ & & & 0.24 \\
\hline
\end{tabular}

effect of intra- and intergenerational departures from ideal conditions was to reduce the effective size to approximately one-quarter of the arithmetic mean population size (i.e., $\left.\left(\alpha_{4}\right)\left(\phi_{4}\right)=\beta_{4}=0.24\right)$.

When population size is not constant, the harmonic mean population size will always be less than the arithmetic mean population size (e.g., Kendall et al. 1994), and $\phi$ will be $<1$. The ratio $\beta$ will always be $<\alpha$, therefore, unless census sizes are constant.

Influence of Population Bottlenecks and Expansions on $\alpha, \beta$, and $\phi$

Population fluctuation may be viewed as reducing $N_{e}$ and $\phi$, but the effects of population bottlenecks (a rapid decrease in population size) and expansions (a rapid increase in population size) have statistical properties that may be counterintuitive (Table 3). The effect of these special types of population fluctuations can be explored by examining two hypothetical populations with a con-

Table 3. Interactions between population fluctuations, $N_{e, t} / N_{t}, \alpha_{4}$, $\phi_{4}$, and $\beta_{4}$ in hypothetical populations.

\begin{tabular}{|c|c|c|c|c|c|c|}
\hline \multirow[b]{2}{*}{ Generation } & \multicolumn{3}{|c|}{$\begin{array}{c}\text { Population w/ } \\
\text { bottleneck }\end{array}$} & \multicolumn{3}{|c|}{$\begin{array}{c}\text { Population w/ } \\
\text { explosion }\end{array}$} \\
\hline & $\mathbf{N}_{\mathrm{t}}$ & $\mathrm{N}_{\mathrm{e}, \mathrm{t}}$ & $\mathrm{N}_{\mathrm{e}, \mathrm{t}} / \mathrm{N}_{\mathrm{t}}$ & $N_{t}$ & $\mathrm{~N}_{\mathrm{e}, \mathrm{t}}$ & $\mathrm{N}_{\mathrm{e}, \mathrm{t}} / \mathrm{N}_{\mathrm{t}}$ \\
\hline \multicolumn{7}{|l|}{ Constant $N_{e, t} / N_{t}$} \\
\hline 1 & 400 & 200 & 0.5 & 400 & 200 & 0.5 \\
\hline 2 & 400 & 200 & 0.5 & 400 & 200 & 0.5 \\
\hline 3 & 40 & 20 & 0.5 & 4000 & 2000 & 0.5 \\
\hline 4 & 400 & 200 & 0.5 & 400 & 200 & 0.5 \\
\hline$\left(N_{e}\right)_{4}$ & & 61.5 & & & 258.1 & \\
\hline$\alpha_{4}$ & & & 0.50 & & & 0.50 \\
\hline$\phi_{4}$ & & & 0.40 & & & 0.40 \\
\hline$\beta_{4}$ & & & 0.20 & & & 0.20 \\
\hline \multicolumn{7}{|l|}{ Variable $N_{e, t} / N_{\mathrm{t}}$} \\
\hline 1 & 400 & 200 & 0.5 & 400 & 200 & 0.5 \\
\hline 2 & 400 & 200 & 0.5 & 400 & 200 & 0.5 \\
\hline 3 & 40 & 40 & 1.0 & 4000 & 4000 & 1.0 \\
\hline 4 & 400 & 200 & 0.5 & 400 & 200 & 0.5 \\
\hline$\left(N_{e}\right)_{4}$ & & 100.0 & & & 262.3 & \\
\hline$\alpha_{4}$ & & & 0.81 & & & 0.51 \\
\hline$\phi_{4}$ & & & 0.40 & & & 0.40 \\
\hline$\beta_{4}$ & & & 0.32 & & & 0.20 \\
\hline
\end{tabular}

stant size of 400 except for a one-generation bottleneck or expansion. For simplicity, we assume that $N_{e, t} / N_{t}$ has been constant and equal to 0.5 each generation. These populations would therefore have had an effective size of 200 if there had been no bottleneck or expansion ( $\mathrm{Ta}$ ble 3). A one-generation bottleneck that reduces population size to one-tenth its normal value lowers the multigeneration effective size from 200 to approximately 62 . A one-generation population explosion that increases the population ten-fold only increases the four-generation effective size to approximately 258 . Because we assumed that $N_{e, t} / N_{t}$ was constant, $\alpha_{4}$ is unaffected by either event. In contrast, both the bottleneck and the expansion cause $\phi_{4}$ to equal 0.4 and $\beta_{4}$ to equal 0.2 . The complexity of these ratios is illustrated by the observation that neither $\alpha_{4}, \phi_{4}$, nor $\beta_{4}$ behave similarly to $\left(N_{e}\right)_{4}$ in this example. The bottleneck decreased $\left(N_{e}\right)_{4}, \phi_{4}$, and $\beta_{4}$, whereas the explosion increased $\left(N_{e}\right)_{4}$ but decreased $\phi_{4}$ and $\beta_{4}$.

\section{Effect of Variation in $N_{e, t} / N_{t}$ on $\alpha, \beta$, and $\phi$}

To examine how variation in $N_{e, t} / N_{t}$ affects $N_{e}, \alpha, \beta$, and $\phi$, we return to our simple example of a population bottleneck and expansion: the most common size of the population was 400 and $N_{e, t} / N_{t}$ was 0.5 each generation (Table 3). Now we consider the consequences of a bottleneck having a $N_{e, t} / N_{t}$ ratio of 1.0 instead of 0.5 (Table $3)$. In this circumstance, the multigeneration effective size increases $60 \%$ from 62 to 100 . If the explosion generation has a $N_{e, t} / N_{t}$ ratio of 1.0 instead of 0.5 , the multigeneration $N_{e}$ increases only slightly from 258 to 262illustrating the fact that generations with smaller $N_{e, t}$ have a strong effect on $N_{e}$. The ratio $\phi_{4}$ is unaffected by variation in $N_{e, t} / N_{t}$ because it is a function of population size only, but $\alpha_{4}$ increases dramatically from 0.5 to 0.81 when the bottleneck generation has an $N_{e, t} / N_{t}$ ratio of 1.0. The ratio $\alpha_{4}$ is largely unaffected by the value of $N_{e, t} / N_{t}$ during the explosion generation. This trend is general: generations with a small population have a disproportionately large influence upon the value of $\alpha$. Nunney (1996) describes $\alpha_{k}$ as factoring out population fluctuation, and this is true if $N_{e, t} / N_{t}$ is constant. If $N_{e, t} /$ $N_{t}$ is variable, however, then $\alpha_{k}$ is affected by population fluctuation in the complex manner that this example illustrates.

Relationship between $\left(N_{e}\right)_{k}, \alpha_{k}$, and $\beta_{k}$ and $\phi_{k}$ and Number of Census Counts

The long-term effective size of a population usually decreases as a population is observed for increasing lengths of time (Vucetich et al. 1997; Vucetich \& Waite 1998). This is because generations with small $N_{e}$ essentially determine the long-term effective size of populations, and, everything else being equal, the longer a pop- 
ulation is observed, the more likely it is to experience a generation of small effective size. The ratio $\beta$ also usually decreases as new data are incorporated (Vucetich et al. 1997; Vucetich \& Waite 1998). If a population does not have a long-term trend of growth or decline, $\left(N_{e}\right)_{k}$ and $\beta_{k}$ will often approach asymptotic values when the population has been observed for a large number of generations (Vucetich et al. 1997; Vucetich \& Waite 1998). This effect can have important consequences for estimating $\left(N_{e}\right)_{\text {as }}$ from a small number of census counts.

To evaluate the effect of the number of census counts on $\left(N_{e}\right)_{k}, \alpha_{k}, \beta_{k}$ and $\phi_{k}$, we considered a simple densitydependent stochastic logistic model of population fluctuation (Dennis \& Taper 1994), parameterized to simulate a population of Grand Teton National Park elk (Cervus elaphus) (Dennis \& Taper 1994). In this example, the population is expected to grow when its size is less than about 1500 individuals and to decline when its size is more than about 1500 . We obtained the effective population size for each generation by assuming that $N_{e, t} / N_{t}$ was independent of census size and normally distributed around 0.5 . We first assigned $N_{e, t} / N_{t}$ a high variance, choosing a value so that $N_{e, t} / N_{t}$ for each generation had a $99 \%$ chance of falling between 0.25 and 0.75 . We ran 10,000 simulations of 1000 generations for this model and calculated the average value of $\left(N_{e}\right)_{k}, \alpha_{k}, \beta_{k}$, and $\phi_{k}$ as $k$ increased. We present results for the first 10 generations only because parameters appeared to quickly approach asymptotic values.

Consistent with results obtained by Vucetich and Waite (1998), we found that the average value of $\left(N_{e}\right)_{k}$ and $\beta_{k}$ decreased steeply toward an asymptote (Fig. 1). In this example $\beta$, approached its asymptote in a few generations. If population size fluctuated more, this approach would require more time. This has important

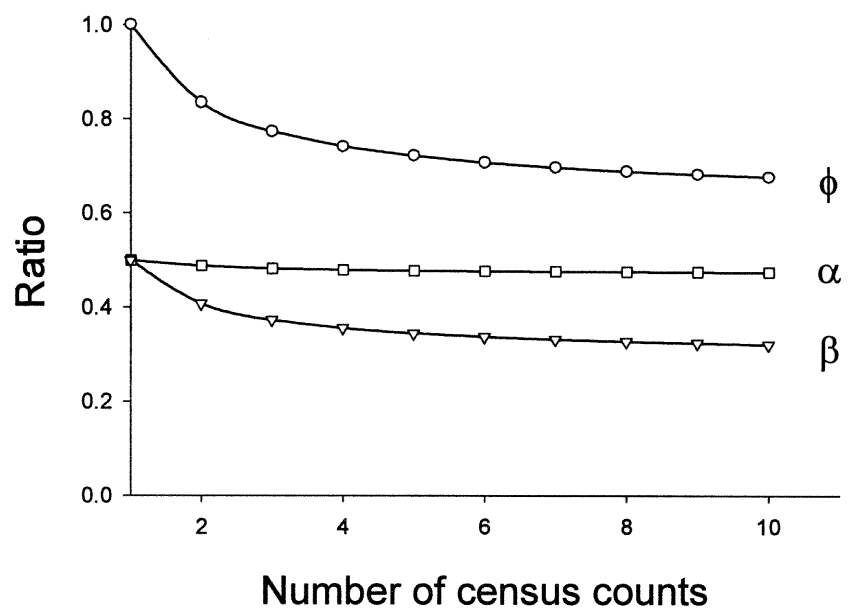

Figure 1. Average value of $\alpha_{\mathrm{k}}, \phi_{\mathrm{k}}$, and $\beta_{\mathrm{k}}$, calculated over an increasing number of census counts for 10,000 simulations of an elk population (Dennis $\varepsilon$ Taper 1994). ramifications for estimating long-term effective sizes from short-term data. In contrast, $\alpha_{k}$ was nearly independent of the number of census counts. The slight decline in $\alpha_{k}$ as increasing numbers of censuses were performed shows that $\alpha_{k}$ can be dependent on the number of census counts even when $N_{e, t} / N_{t}$ is independent of population size. This seems to be because bottlenecks with a low $N_{e, t} / N_{t}$ affect $\alpha_{k}$ more than bottlenecks with the same population size but higher values of $N_{e, t} / N_{t}$ (e.g., Table 3). But the observed decline from 0.50 to 0.48 over 10 generations was slight. When we assigned $N_{e, t} /$ $N_{t}$ a smaller-and probably more realistic-variance, $\alpha_{k}$ was even less sensitive to the number of census counts. This lead us to conclude that if $N_{e, t} / N_{t}$ is independent of census counts, then $\alpha_{k}$ will probably be approximately independent of census counts.

If $N_{e, t} / N_{t}$ is not independent of population size, then $\left(N_{e}\right)_{k}, \alpha_{k}$, and $\beta_{k}$ will all have different statistical properties from those we discussed. For example, if $N_{e, t} / N_{t}$ was expected to be higher during generations with a low census count, then the average value of $\alpha_{k}$ would increase as more data is collected.

\section{Estimating Effective Sizes from Census Data}

The properties of $\alpha, \beta$, and $\phi$ provide a basis for using these ratios to estimate effective sizes (single-generation, multigeneration, and long-term) from census count data. An estimate of the effective size of a single generation, $N_{e, t}$, can be obtained from a census count by multiplying the census count by an appropriate value for $N_{e, t} / N_{t}$. Theoretical arguments (Nunney 1991, 1993, 1996) suggest that $N_{e, t} / N_{t}$ should be approximately 0.5 and seldom $<0.25$ or $>0.75$ in animal populations. Empirical examination (Frankham 1995) appears to support this prediction and shows that different taxa have different values. For example, plants appear to have lower values of $N_{e, t} / N_{t}$ than animals.

A guide to estimating the effective size of a population over multiple generations is the number of terms in equation $7,\left(N_{e}\right)_{k}=(\bar{N})_{k} \alpha_{k} \beta_{k}$, that can be estimated from data available for the population and how many terms must be estimated from theoretical or empirical arguments. Estimating $\left(N_{e}\right)_{k}$ when census data are available is straightforward because $\phi_{k}$ is estimated from the census counts and $\alpha_{k}$ is the only unknown parameter in equation 7. Although $\alpha_{k}$ has not been studied extensively, if $N_{e, t} / N_{t}$ is independent of census size, then most theoretical and empirical discussion of $N_{e, t} / N_{t}$ probably applies to $\alpha_{k}$ as well. For example, if $N_{e, t} / N_{t}$ is independent of census size, then $\alpha_{k}$ should be approximately 0.5 for most animal populations and seldom $<0.25$. Different taxa appear to have different values of $N_{e, t} / N_{t}$ (e.g., Frankham 1995), so reviewing published estimates of $N_{e, t} / N_{t}$ for similar taxa will probably be valuable. If $N_{e, t} / N_{t}$ 
tends to be larger when populations are small (as was observed by Pray et al. 1996), then $\alpha_{k}$ might be larger than expected. Conversely, if $N_{e, t} / N_{t}$ tends to be smaller when populations are small, $\alpha_{k}$ might be smaller than expected. But if $N_{e, t} / N_{t}$ is related to census size, $\alpha_{k}$ will probably be approximately independent of the number of census counts unless $N_{e, t} / N_{t}$ varies widely or the relationship between $N_{e, t} / N_{t}$ and census size is strong.

Estimating the long-term effective size of a population, $\left(N_{e}\right)_{\text {as }}$, from a limited number of census counts requires making more assumptions than estimating $\left(N_{e}\right)_{k}$, because estimating $\left(N_{e}\right)_{\text {as }}$ requires making a statement about the size of the population during generations that have not been observed. In this situation one knows $\phi_{k}$ and has to decide how close this value is to the asymptotic value of $\phi$ (Vucetich et al. 1997; Vucetich \& Waite 1998). If the population has been examined for many generations, then one might assume that most of the population's variability in size has been observed (Pimm \& Redfearn 1988; Arino \& Pimm 1995) and that $\phi_{k}$ is close to its asymptotic value. If the population has been observed for only a short period of time, then asymptotic $\phi$ probably will be less than the observed value of $\phi_{k}$. In this situation, $\phi_{k}$ can be used to approximate a maximum value for asymptotic $\phi$. Another, perhaps better, alternative may be to estimate a confidence interval for the asymptotic value of $\phi$ :

$$
\left[\frac{\phi_{k}\left(\chi_{p_{1}, k}^{2}\right)^{2}}{k \sqrt{\phi_{k}}-k-\sqrt{\phi_{k}}\left(\chi_{p_{1}, k}^{2}\right)^{2}}, \frac{\phi_{k}\left(\chi_{p_{1}, k}^{2}\right)^{2}}{k \sqrt{\phi_{k}}-k-\sqrt{\phi_{k}}\left(\chi_{p_{2}, k}^{2}\right)}\right],
$$

where $\chi_{p, k}^{2}$ refers to the $p$ th percentile of the chi-square distribution with $k$ degrees of freedom (Vucetich $\&$ Waite 1998).

Estimating the long-term effective size of a population, $\left(N_{e}\right)_{k}$, when only the arithmetic mean census size is available is substantially more difficult than when census counts are available, because both $\alpha_{k}$ and $\phi_{k}$ are unknown in this circumstance. Once again, obtaining a reasonable estimate for $\phi_{k}$ is complicated by the dependence of $\phi_{k}$ on the number of census counts. Furthermore, empirical reviews (Pimm \& Redfearn 1988; Frankham 1995; Vucetich et al. 1997; Vucetich $\&$ Waite 1998) show that $\phi_{k}$ varies widely across species. These reviews suggest that the asymptotic value for $\phi_{k}$ has an average value of 0.45 across species, so this value might be used if enough generations have been censused. If only a few generations have been censused, then a larger value might be used.

\section{Conclusions}

We began this investigation by proposing two biologically meaningful definitions for $N_{e} / N$ ratios in fluctuat- ing populations: $\alpha$, the value that $N_{e, t} / N_{t}$ would have if it were constant each generation, and $\beta$, a description of how much each real individual contributed to the effective population size. These biological definitions led naturally to mathematical representations incorporating harmonic $(\alpha)$ and arithmetic $(\beta)$ mean population sizes, which, conveniently, are the ratios used in previous research. Next, we showed that $\beta$ is simply $\alpha$ times a ratio $(\phi)$ that reflects how much the population fluctuated in size. Each ratio is affected by population fluctuation, but in fundamentally different ways: $\beta$ is reduced by population fluctuation itself, whereas $\alpha$ is reduced by small values of $N_{e, t} / N_{t}$, particularly in generations of small size. Understanding these properties will be essential in using $\alpha$ and $\beta$ to monitor or manage genetic diversity in small populations.

An important question remaining in effective-size theory is how $N_{e, t} / N_{t}$ ratios vary in natural populations. A better understanding of this relationship would be useful in predicting the effect of population bottlenecks on genetic variation in populations. For example, high $N_{e, t} /$ $N_{t}$ ratios during bottlenecks would reduce the effect of genetic drift. Pray et al. (1996) observed this in small experimental populations of the red flour beetle (Tribolium castaneum), but their study design did not address how ecological determinants of population size might affect $N_{e, t} / N_{t}$. Therefore, further exploration of this relationship would be valuable.

\section{Acknowledgments}

We thank E. Anderson, C. Do, M. Ford, R. Frankham, P. Hedrick, L. Nunney, J. Vucetich, and two anonymous reviewers for comments that improved this manuscript.

\section{Literature Cited}

Arino, A., and S. L. Pimm. 1995. On the nature of population extremes. Evolutionary Ecology 9:429-443.

Caballero, A. 1994. Developments in the prediction of effective population size. Heredity 73:657-679.

Crow, J. F., and M. Kimura. 1970. An introduction to population genetics theory. Harper and Row, New York.

Dennis, B., and M. L. Taper. 1994. Density dependence in time series observations of natural populations: estimation and testing. Ecological Monographs 64:205-224.

Frankham, R. 1995. Effective population size/adult population size ratios in wildlife: a review. Genetical Research 66:95-107.

Kendall, M. G., A. Stuart, and J. K. Ord. 1994. Kendall's advanced theory of statistics, 6th edition. Halsted Press, New York.

Motro, U., and G. Thompson. 1982. On heterozygosity and the effective size of populations subject to size changes. Evolution 36: 1059-1066.

Neigel, J. E. 1996. Estimation of effective population size and migration parameters from genetic data. Pages $329-346$ in T. B. Smith and R. K. Wayne, editors. Molecular genetic approaches in conservation. Oxford University Press, Oxford, United Kingdom.

Nunney, L. 1991. The influence of age structure and fecundity on ef- 
fective population size. Proceedings of the Royal Society of London Series B. 246:71-76.

Nunney, L. 1993. The influence of mating system and overlapping generations on effective population size. Evolution 47:1329-1341.

Nunney, L. 1996. The influence of variation in female fecundity on effective population size. Biological Journal of the Linnean Society 59:411-425.

Pimm, S. L., and A. Redfearn. 1988. The variability of population densities. Nature 334:613-614.

Pray, L. A., C. J. Goodnight, L. Stevens, J. M. Schwartz, and G. Yan. 1996. The effect of population size on effective population size: an empirical study in the red flour beetle Tribolium castaneum. Genetical Research 68:151-155.

Vucetich, J. A., and T. A. Waite. 1998. Number of censuses required for demographic estimation of effective population size. Conservation Biology 12:1023-1030.

Vucetich, J. A., T. A. Waite, and L. Nunney. 1997. Fluctuating population size and the ratio of effective to census population size $\left(N_{e} / N\right)$. Evolution 51:2015-2019.

Wright, S. 1931. Evolution in Mendelian populations. Genetics 16:97-159. Wright, S. 1938. Size of a population and breeding structure in relation to evolution. Science 87:430-431.

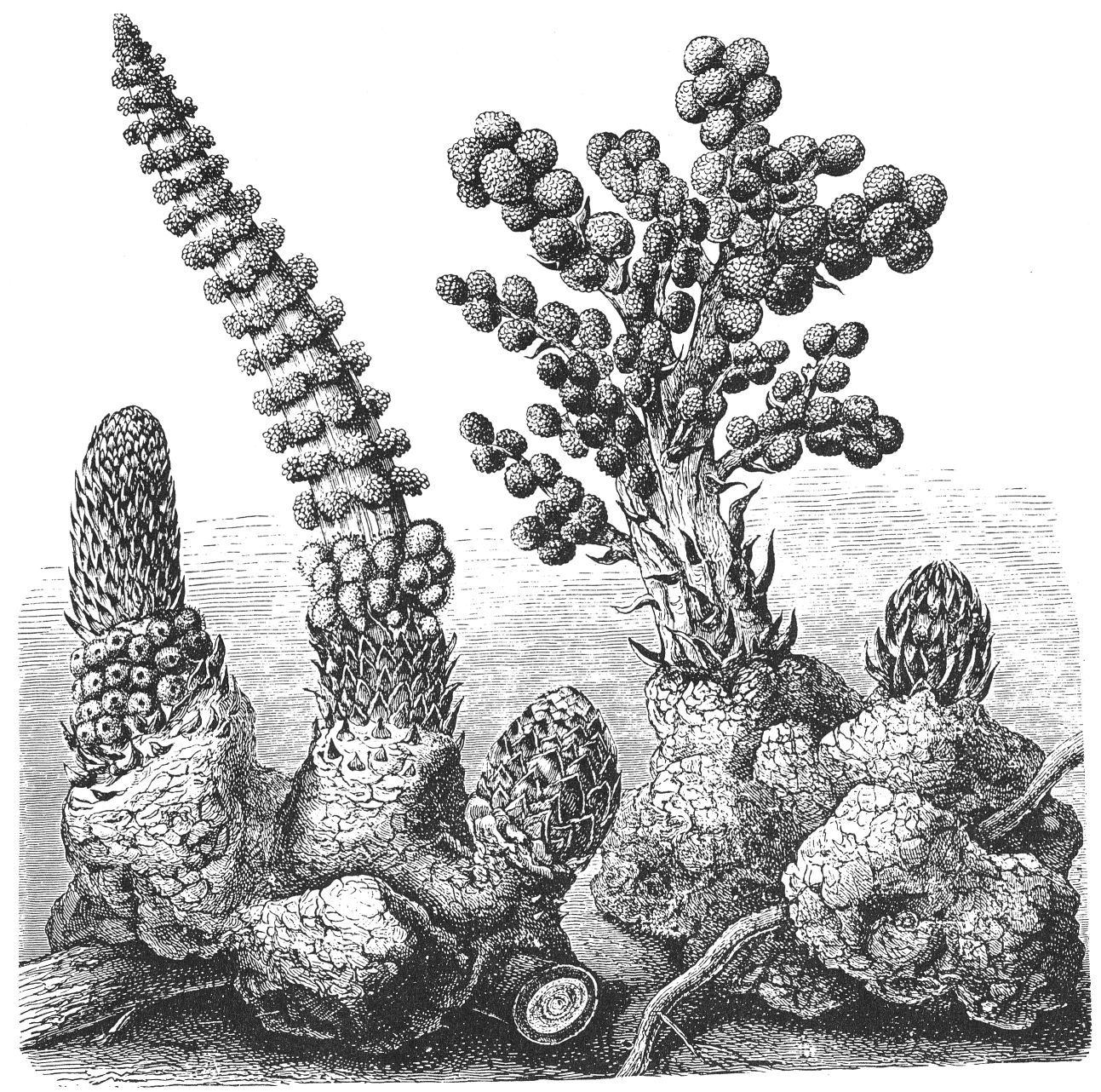

